\title{
Effects of Soil Characteristics on Metribuzin Dissipation Using Clay-Gel-Based Formulations
}

\author{
Celia Maqueda,* Jaime Villaverde, Fátima Sopeña, Tomás Undabeytia, \\ AND ESMERALDA MORILLO
}

Instituto de Recursos Naturales y Agrobiología de Sevilla, Consejo Superior de Investigaciones Científicas (CSIC), Post Office Box 1052, Sevilla 41080, Spain

\begin{abstract}
Metribuzin (MTB) is a herbicide widely used for weed control in growing soybeans and other crops and has been identified in many parts of the world as a groundwater contaminant. To prepare controlled-release formulations (CRFs) of MTB, it was entrapped within a sepiolite-gel-based matrix with one of two proportions of clay/herbicide and used as either a gel or powder after freeze-drying. To determine how its persistence in soil is affected by formulation and soil type, MTB was applied as a CRF or commercial formulation (CM) to soils with different properties. MTB dissipation in all soils investigated was reduced when the herbicide was applied as CRFs, especially in the case of sandy soil and the freeze-dried formulations, with $\mathrm{DT}_{50}$ values of 57.5 and 104.1 days, respectively, versus 24.8 days for $\mathrm{CM}$. A positive relationship between degradation rates, bioactivity, and soil $\mathrm{pH}$ was found. MTB adsorption-desorption studies on these soils were also performed, and no relationship between adsorption-desorption and the degradation rate of MTB was found, possibly because of the low adsorption capacity of the studied soils. MTB when applied as a CRF remains active longer than $\mathrm{CM}$, avoiding the need to use more frequently herbicide applications.
\end{abstract}

KEYWORDS: Metribuzin; controlled release formulation; sepiolite; adsorption-desorption; dissipation

\section{INTRODUCTION}

Metribuzin (MTB) is a herbicide widely used for weed control in growing soybeans, potatoes, tomatoes, and other crops. Because of its relatively high water solubility $\left(1050 \mathrm{mg} \mathrm{L}^{-1}\right)$, MTB may leach into the soil and eventually into the groundwater $(1,2)$. In addition to leaching, MTB may be dissipated in the soil via its degradation through chemical and biological processes. In general, the degradation of herbicides is influenced by many factors, such as chemical concentration, diffusion, adsorption-desorption, soil type, and climatic conditions, while microbial breakdown is the main cause of MTB dissipation in soils (3). On soil surfaces under natural light conditions, the half-life of MTB is 14-25 days (3).

Unlike classical formulations, controlled release formulations (CRFs) gradually release pesticides, which permits a lower concentration of active ingredient to be released into the environment, while at the same time, provide enough to maintain biological efficacy. The use of CRFs would be expected to improve environmental safety and perhaps efficacy as well (4-7). Previous studies have reported the preparation of MTB CRFs through the use of granular formulations of alginate beads and/ or alginate-kaolin-linseed oil, from which the MTB release rate was considerably reduced $(8-11)$. CRFs based on the intercalation of polymeric MTB into montmorillonite have also been carried out by Rehab et al. (12).

* To whom correspondence should be addressed. Telephone: 34954624711. Fax: 34-954624002. E-mail: celia@irnase.csic.es.
Clay minerals have been used for the CRFs of several herbicides. Numerous studies have focused on the use of modified montmorillonite by pre-adsorbing organic cations as a support system for slow release; however, the organic cations used in the synthesis of organo-montmorillonite are not considered to be of minimal toxicological risk $(13,14)$.

Sepiolite is a microfibrous hydrated $\mathrm{Mg}$ phylosilicate with a theoretical unit cell formula $\mathrm{Si}_{12} \mathrm{O}_{30} \mathrm{Mg}_{8}(\mathrm{OH}, \mathrm{F})_{4}\left(\mathrm{OH}_{2}\right)_{4} 8 \mathrm{H}_{2} \mathrm{O}$ (15). It is formed by the alternation of blocks and tunnels growing in the directions of the fibers. Each structural block is composed of two tetrahedral silica sheets and a central octahedral sheet containing magnesium. The discontinuity of the silica sheet gives rise to the structural tunnels. Silanol groups $(\mathrm{Si}-\mathrm{OH})$ are on the external surface of the silicate particles and are thus accessible to reagents. Sepiolite has a high Brunauer-Emmett-Teller (BET) surface area $\left(300 \mathrm{~m}^{2} \mathrm{~g}^{-1}\right)$ that allows for the adsorption of molecules such as pesticides (16). Most published studies addressing the influence of soil characteristics on MTB persistence have been carried out on pure or commercial formulations of the chemical $(17,18)$. However, little data have been reported about the behavior of MTB CRFs in soil $(9,10)$, especially with regard to their persistence. To address this issue, MTB was entrapped within a claysepiolite-gel to prepare CRFs having one of two clay/herbicide proportions (loaded at 28.6 or $16.7 \%$ of herbicide) using a novel, useful, and economic ultrasound-based technique. In the current work, we study the influence of soil characteristics on the 


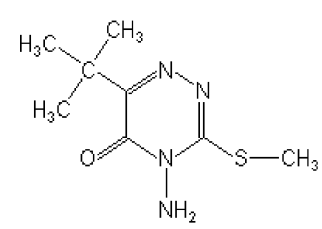

a)

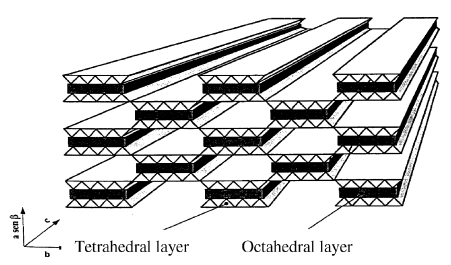

b)
Figure 1. Structural formulas of the (a) herbicide MTB and (b) sepiolite structure.

Table 1. Physicochemical Properties and Bioactivity of the Soils Used

\begin{tabular}{lcrrrrrr}
\hline \multicolumn{1}{c}{ soil } & $\mathrm{pH}$ & $\begin{array}{c}\mathrm{CaCO}_{3} \\
(\%)\end{array}$ & $\begin{array}{c}\mathrm{OM}^{a} \\
\left(\mathrm{~g} \mathrm{~kg}^{-1}\right)\end{array}$ & $\begin{array}{c}\text { sand } \\
\left(\mathrm{g} \mathrm{kg}^{-1}\right)\end{array}$ & $\begin{array}{c}\text { silt } \\
\left(\mathrm{g} \mathrm{kg}^{-1}\right)\end{array}$ & $\begin{array}{c}\text { clay } \\
\left(\mathrm{g} \mathrm{kg}^{-1}\right)\end{array}$ & $\begin{array}{c}\mathrm{DA}^{b} \text { [mg of TPF } \\
\left(\mathrm{kg}^{2} \text { of soil }\right)^{-1} \\
\left.\text { day }^{-1}\right]\end{array}$ \\
\hline silt loam & 6.0 & 0.0 & 14.1 & 167 & 586 & 247 & $2.7 \pm 0.1$ \\
sandy & 7.8 & 8.6 & 7.0 & 953 & 20 & 26 & $3.1 \pm 0.2$ \\
clay & 8.0 & 24.1 & 17.6 & 27 & 315 & 659 & $13.6 \pm 2.5$
\end{tabular}

${ }^{a}$ Organic matter content. ${ }^{b}$ Dehydrogenase activity.

persistence of MTB derived from the new clay-gel-based formulations versus the commercial formulation. Additionally, a study of MTB adsorption-desorption in soil was performed to investigate the potential link between these processes and MTB degradation, as well as a study examining the influence of the type of MTB formulation on soil dissipation.

\section{MATERIALS AND METHODS}

Materials. MTB (4-amino-6-tert-butyl-3-methylthio-1,2,4-triazin$5(4 H)$-one) (technical grade, 93\%) and commercial formulation (ECLIPSE) as a wettable granulate were provided by Presmar S.L.

Sigma Aldrich (Madrid, Spain) was the source of 2,3,5-thriphenyl$2 \mathrm{H}$-tretrazolium chloride (TTC), 1,3,5-thriphenyltetrazolium formazane (TPF), and tris(hydroxymethyl)aminomethane (Tris). All solvents used were of high-performance liquid chromatography (HPLC) grade.

The clay mineral used was sepiolite of Vicalvaro obtained from Tolsa S.A. The sepiolite was crushed to a particle size $<150 \mu \mathrm{m}$.

The structural formulas of the herbicide and sepiolite structure are shown in Figure 1.

All of the soils used were from southwestern Spain and classified according to the Soil Survey Staff (19). The silt loam soil (Aquic Dystric Eutrochrept) was collected near Aracena (Huelva) $\left(37^{\circ} 53^{\prime} 00^{\prime \prime} \mathrm{N}\right.$, $06^{\circ} 28^{\prime} 31^{\prime \prime} \mathrm{W}$ ); the sandy soil (Typic Xeropsament) was obtained from the experimental farm "La Hampa" of Coria (Sevilla) (37 $16^{\prime} 59^{\prime \prime} \mathrm{N}$, $06^{\circ} 04^{\prime} 03^{\prime \prime} \mathrm{W}$ ); and the clay soil (Chromic Haploxerert) was collected from the experimental farm "Las Torres" of Carmona (Sevilla) $\left(37^{\circ} 24^{\prime} 07^{\prime \prime} \mathrm{N}, 05^{\circ} 35^{\prime} 10^{\prime \prime} \mathrm{W}\right)$.

Samples were collected from the soil surface, at a depth of 0-20 $\mathrm{cm}$, and crushed to pass through a $2 \mathrm{~mm}$ sieve. They were analyzed for $\mathrm{pH}$, total carbonate content, particle size distribution, and organic matter (OM) content (Table 1). Particle-size distribution was measured by the Bouyoucos densimeter (20); OM was measured by potassium dichromate oxidation; $\mathrm{pH}$ was measured using a 1:2.5 soil/water extract; and total carbonate content was measured by a manometric method (21).

Methods. Clay-Gel-Based Formulation Preparation. The formulations were prepared by mixing 0.5 or $1 \mathrm{~g}$ of sepiolite in a cooling reactor with $200 \mathrm{mg}$ of MTB dissolved in $100 \mathrm{~mL}$ of a mixture 80:20 distilled water/ethanol. Afterward, the mixture underwent an ultrasonic treatment as described by Maqueda et al. (22). Briefly, a Misonix ultrasonic liquid processor of $600 \mathrm{~W}$ output with a $20 \mathrm{kHz}$ converter and a tapped titanium disruptor horn of $12.7 \mathrm{~mm}$ in diameter was used to obtain a gel texture. The temperature of the reactor was kept constant at $20^{\circ} \mathrm{C}$ by means of cooling recirculation during the entire treatment. The resulting formulations contained 16.7 or $28.6 \%$ of active ingredient (a.i.); these formulations are hereafter referred to as G1 and G0.5, respectively.
Freeze-Dried Herbicide Clay-Gel Formulations. Part of the obtained clay-gel formulations were placed in a freezer for $24 \mathrm{~h}$ and then freezedried (formulations denoted as LF0.5 and LF1, correspoding to 28.6 or $16.7 \%$ of a.i.). After the formulations were freeze-dried, MTB was extracted with methanol $(1: 2, w / v)$, with the aim of checking the possible herbicide losses. More than $95 \%$ of MTB was recovered. The extraction efficiency of the method was $95.8 \pm 1.5 \%$. MTB extraction were carried out in triplicate.

Analytical Methods. HPLC Analysis. HPLC was employed for the analysis of MTB. The conditions were as follows: mobile phase, acetonitrile/water (60:40); flow, $0.6 \mathrm{~mL} / \mathrm{min}$; temperature, $30{ }^{\circ} \mathrm{C}$; chromatographic colunms kromasil $\mathrm{C} 18$ reverse phase; and for detection, a Shimadzu 2010 AHT series UV detector with a wavelength of $254 \mathrm{~nm}$.

Microbiological Analysis of Soil. Soil bioactivity was evaluated by measuring the dehydrogenase activity (DA) for all soils used in the dissipation experiments (Table 1). This enzyme is active only in living organisms and is an indicator of soil microbial activity.

The DA assay was performed in triplicate after 2 weeks of incubation. Soil samples $(5 \mathrm{~g})$ were incubated at $30^{\circ} \mathrm{C}$ with $5 \mathrm{~mL}$ of colorless TTC solution ( $0.5 \%$ by weight $)$ in $0.1 \mathrm{M}$ Tris buffer adjusted to $\mathrm{pH} 7.6$ with $\mathrm{HCl}$. TTC was reduced by dehydrogenase enzymes to become the red, water-insoluble TPF, which was extracted with 25 $\mathrm{mL}$ of acetone after $24 \mathrm{~h}$ of incubation. The samples were shaken for $1.0 \mathrm{~h}$ and centrifuged at $5000 \mathrm{~g}$ for $12 \mathrm{~min}$. The intensity of the red color of the supernatant was measured by spectrophotometry at 485 $\mathrm{nm}$ and converted to bioactivity [mg of TPF $(\mathrm{kg} \text { of soil })^{-1}$ ] based on a set of TPF standards.

Experiments. MTB Adsorption-Desorption Studies on Soil. Adsorption experiments were performed in triplicate by mixing $10 \mathrm{~g}$ of the soil with $20 \mathrm{~mL}$ of $0.01 \mathrm{M} \mathrm{Ca}\left(\mathrm{NO}_{3}\right)_{2}$ solution containing various concentrations $\left(1,3,5,7\right.$, and $\left.10 \mathrm{mg} \mathrm{L}^{-1}\right)$ of MTB, in $50 \mathrm{~mL}$ polypropylene centrifuge tubes. The samples were shaken for $24 \mathrm{~h}$ at $20 \pm 1{ }^{\circ} \mathrm{C}$. This reaction duration was chosen from preliminary kinetic studies (not shown), which showed that, by this time, adsorption had reached pseudo-equilibrium. After shaking on a platform shaker, the suspensions were centrifuged and the concentration of MTB in the supernatant was determined by HPLC. The difference in pesticide concentration between the initial and final equilibrium solutions was assumed to be due to sorption, and the amount of MTB retained by the soil was calculated.

Desorption experiments were performed after adsorption equilibrium was reached for the points corresponding to initial MTB concentrations of 1,5 , and $10 \mathrm{mg} \mathrm{L}^{-1}$, by removing half of the supernatant after centrifugation, replacing it with $10 \mathrm{~mL}$ of $0.01 \mathrm{M} \mathrm{Ca}\left(\mathrm{NO}_{3}\right)_{2}$ solution, allowing equilibration for an additional $24 \mathrm{~h}$ period, and then proceeding as in the adsorption experiment. This process was repeated twice.

Sorption-desorption isotherms were fitted to the logarithmic form of the Freundlich equation

$$
\log \mathrm{Cs}=\log K_{\mathrm{f}}+n \log \mathrm{Ce}
$$

where $\mathrm{Cs}\left(\mu \mathrm{mol} \mathrm{kg} \mathrm{kg}^{-1}\right)$ is the amount of herbicide sorbed at the equilibrium concentration $\mathrm{Ce}\left(\mu \mathrm{mol} \mathrm{L}{ }^{-1}\right)$ and $K_{\mathrm{f}}$ and $n$ are constants that characterize the relative sorption capacity and the sorption intensity, respectively, of the herbicide.

Hysteresis coefficients, $H$, for the sorption-desorption isotherms were calculated according to

$$
H=\mathrm{na} / \mathrm{nd}
$$

where na and nd are the Freundlich $n$ constants obtained from the sorption and desorption isotherms, respectively. This na/nd ratio has also been used by other authors to describe the hysteretic behavior of desorption from soils (23-26).

Water Release Studies. To compare the release behavior of the different formulations obtained, dissolution tests of the commercial MTB formulation (CM) and all clay-gel-based formulations (G0.5, G1, LF0.5, and LF1) were performed in triplicate with a rotate paddle apparatus (Sotax). Formulations containing $10 \mathrm{mg}$ of MTB were added to $500 \mathrm{~mL}$ of deionized water. The gel formulations were placed in 
dialysis bags, and the freeze-dried formulations were added directly to the water as a powder. At appropriate intervals, $1 \mathrm{~mL}$ samples were taken and replaced by distilled water to maintain a constant volume. The samples were analyzed by HPLC as described below.

Dissipation Experiments in Soil. The herbicide dissipation rate of $\mathrm{CM}$ and clay-gel-based formulations was tested for three soils (sandy, silt loam, and clay). The objective was to determine the influence of soil properties on the dissipation of MTB. This study is significant from an agricultural perspective because realistic herbicide concentrations were applied. The initial concentration of all formulations and soils was $1.6 \mathrm{mg}$ of a.i. $\left(\mathrm{kg}\right.$ of $\left.\mathrm{soil}^{-1}\right)$, which corresponds to a field application rate of $2 \mathrm{~kg}$ of a.i. ha ${ }^{-1}$, assuming that the herbicide is incorporated in the top $10 \mathrm{~cm}$ of the soil, with an average bulk density of $1200 \mathrm{~kg}$ $\mathrm{m}^{-3}$.

Soil samples ( $200 \mathrm{~g}$ each) were mixed in triplicate with $0.4 \mathrm{mg}$ of MTB ( $2 \mathrm{mg} \mathrm{kg}$ of soil $\left.{ }^{-1}\right)$ and then shaken thoroughly for $24 \mathrm{~h}$. After mixing, the samples were transferred to plastic pots, covered with aluminum foil, and stored in an incubator (BINDER KBWF 720, humidity atmosphere of $80 \%$ ) in the dark for 80 days at $25^{\circ} \mathrm{C}$. The soil moisture content was maintained at field capacity by periodic additions of water. Soil samples $(10 \mathrm{~g}$ each) were taken at different time points $(0,7,14,21,28,55$, and 80 days $)$ and stored at $-20{ }^{\circ} \mathrm{C}$ until analysis. Before sampling, the soil was thoroughly mixed. MTB was then extracted from the soil samples with methanol and analyzed by HPLC. Three kinetic models were fitted to the degradation curves: a simple first-order equation, a first-order multicompartment model (Gustafson and Holden), and a first-order sequential model (HockeyStick). Parameters were optimized according to recommendations by FOCUS (27), using the least-squares method with Microsoft Excel Solver. The simple first-order kinetic model always described the data adequately (and often better than the other two models). The firstorder rate of degradation and the $\mathrm{DT}_{50}$ (time required for $50 \%$ of the initial dose of herbicide to be degraded) of each formulation in each soil were determined with the following equations:

$$
\begin{gathered}
\ln C=\ln C_{0}-k t \\
\mathrm{DT}_{50}=\ln 2 / k
\end{gathered}
$$

where $C$ is the concentration of herbicide remaining in the soil $(\mathrm{mg}$ $\left.\mathrm{kg}^{-1}\right)$ after $t$ days, $C_{0}$ is the initial concentration of pesticide $\left(\mathrm{mg} \mathrm{kg}^{-1}\right)$, and $k$ is the rate of degradation $\left(\right.$ day $\left.^{-1}\right)$.

\section{RESULTS AND DISCUSSION}

Adsorption-Desorption Experiments. Figure 2 shows the sorption-desorption isotherms of MTB in the three soils studied. The isotherms were $L$ type (concave initial curvature) according to the classification of Giles et al. (28). In all cases, MTB adsorption isotherms were well-described by the linearized Freundlich equation (Table 2). The sorption isotherms were compared using the $K_{\mathrm{f}}$ parameter of the Freundlich equation. The constant $K_{\mathrm{f}}$ is the amount of pesticide sorbed for an equilibrium concentration of $1 \mu \mathrm{mol} \mathrm{L}{ }^{-1}$ and, hence, represents adsorption at low adsorbate concentrations. $K_{\mathrm{f}}$ values can be used to compare the adsorption capacity of the different soils studied. The reported values indicate a low retention of MTB in these soils and, thus, a high potential mobility in the soil. Soil adsorption capacity increased in the following order: sandy $<$ silt loam $\leq$ clay

MTB adsorption has been previously related to the OM content of soil (29), and the $K_{\mathrm{f}}$ value of our isotherms indicated that the affinity of the clay soil for MTB was related to the OM content, because the soil with higher $K_{\mathrm{f}}$ is the soil with more OM. However, strong correlations have sometimes been found between the clay content and the adsorption of MTB. For instance, Harper (30) studied the behavior of the adsorption of MTB on a silty clay loam soil with a low level of OM and observed that the clay content was the single best predictor of
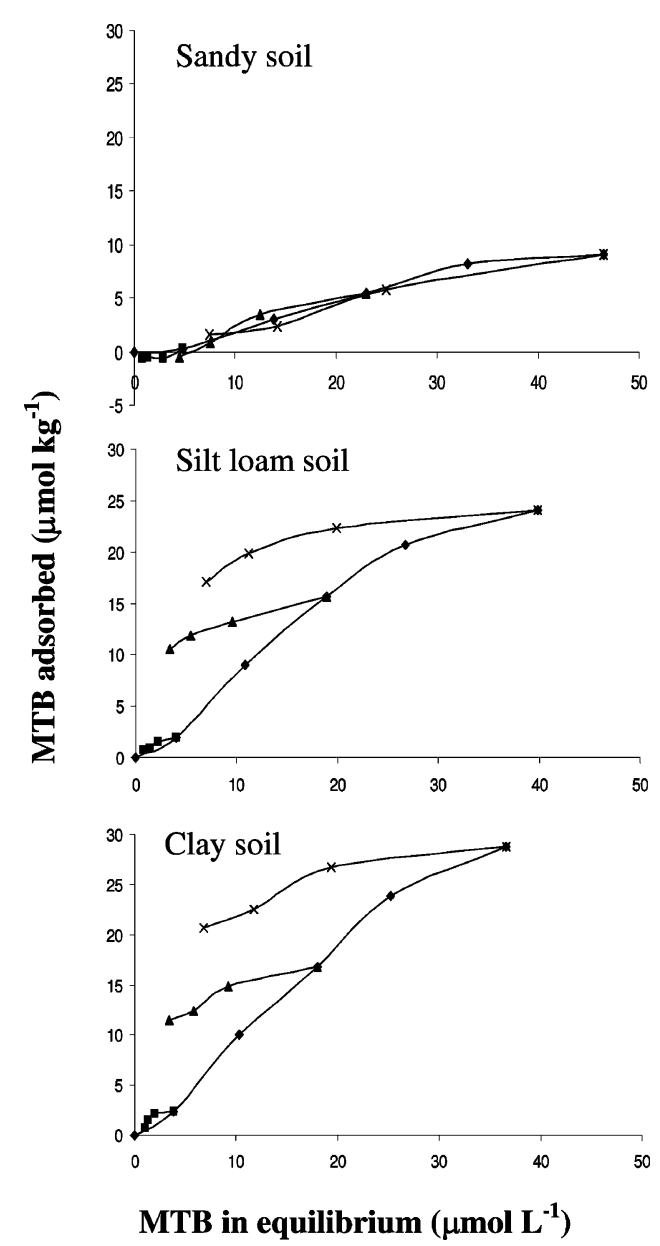

Figure 2. MTB adsorption-desorption isotherms on soils.

Table 2. Freundlich Adsorption Isotherm Parameters of MTB Sorption on the Soils Used

\begin{tabular}{lcc}
\hline \multicolumn{1}{c}{ soils } & $K_{\mathrm{f}}$ & $n$ \\
\hline sandy & $0.32 \pm 0.08$ & $0.891 \pm 0.12$ \\
silt loam & $1.45 \pm 0.15$ & $0.883 \pm 0.17$ \\
clay & $1.54 \pm 0.13$ & $0.762 \pm 0.18$
\end{tabular}

its adsorption. Indeed, in low OM soils, the contribution of the inorganic constituents to pesticide retention can be significant (31). The soils in the current study have low OM contents (Table 1), and therefore, the clay content in these soils would also influence the MTB adsorption prediction.

MTB desorption from two of the investigated soils (clay and silt loam) was hysteretic (Figure 2); that is, the desorption behavior deviated markedly from that of the adsorption isotherms, indicating that MTB adsorption in these soils was not completely reversible. This failure to completely recover adsorbed MTB has also been reported by Selim (32) for silt loam soil. Desorption isotherms were also described by the Freundlich equation (eq 1), and hysteresis coefficients were calculated according to eq 2 . Hysteresis coefficients $(H)$ and the percentage of MTB desorbed with respect to that previously adsorbed during the adsorption process $(\% \mathrm{D})$ are shown in Table 3.

Of particular note is the case of sandy soil, where $100 \%$ of the MTB was desorbed for all equilibrium concentrations, leading us to conclude that soil properties should be taken into consideration to predict the soil desorption capacity, especially $\mathrm{OM}$ and clay content. For the other two soils, similar \%D values were obtained for all initial MTB concentrations used. Likewise, 
Table 3. Percentage of MTB Desorbed (\%D) and Hysteresis Coefficients (H) for the Soils Studied

\begin{tabular}{|c|c|c|c|c|c|c|}
\hline \multirow[b]{2}{*}{ soil } & \multicolumn{3}{|c|}{$\% D$} & \multicolumn{3}{|c|}{$H$} \\
\hline & $1 \mathrm{mg} \mathrm{L}^{-1}$ & $5 \mathrm{mg} \mathrm{L}^{-1}$ & $10 \mathrm{mg} \mathrm{L}^{-1}$ & $1 \mathrm{mg} \mathrm{L}^{-1}$ & $5 \mathrm{mg} \mathrm{L}^{-1}$ & $10 \mathrm{mg} \mathrm{L}^{-1}$ \\
\hline silt loam & $68.9_{( \pm 0.4)}$ & $31.8_{( \pm 0.9)}$ & $28.1_{( \pm 0.8)}$ & 1.5 & 4.5 & 4.4 \\
\hline sandy & $100.0_{( \pm 0.3)}$ & $100.0_{( \pm 0.5)}$ & $100.0_{( \pm 4.8)}$ & 0.8 & 1.7 & 0.6 \\
\hline clay & $64.6_{( \pm 0.5)}$ & $32.6_{( \pm 0.4)}$ & $29.0_{( \pm 1.6)}$ & 1.5 & 5.2 & 5.4 \\
\hline
\end{tabular}

the lowest $H$ values were observed for the sandy soil, indicating the reversible adsorption behavior of this herbicide in the sandy soil.

Influence of MTB Formulation on Its Dissipation in Soil. Parts $\mathbf{a}$ and $\mathbf{b}$ of Figure $\mathbf{3}$ show the influence of the formulation type and formulation loading on the MTB release into water. The release of MTB from CRFs was retarded in comparison to the commercial formulation, except for the G0.5 formulation, which showed retarded release only in the first few hours after the experiment was started, with a final release similar to that of $\mathrm{CM}(\sim 100 \%)$. The release rates of the gel formulations were dramatically affected by the clay/MTB ratio, as shown in Figure 3a. The gels prepared using $0.5 \mathrm{~g}$ of sepiolite (G0.5) showed lower viscosity than those prepared with $1 \mathrm{~g}$ of sepiolite, which would imply higher diffusion rates in the case of G0.5 formulation over that from the higher viscosity formulation G1. However, the freeze-dried formulation prepared with $0.5 \mathrm{~g}$ of sepiolite (LF0.5) showed a slow release similar to that of the corresponding gel formula, because of the collapse during this treatment of the fibers, which would have strongly entrapped the herbicide and impeded its release into water. The data show that the type of formulation affects the release of MTB into water more than herbicide loading.
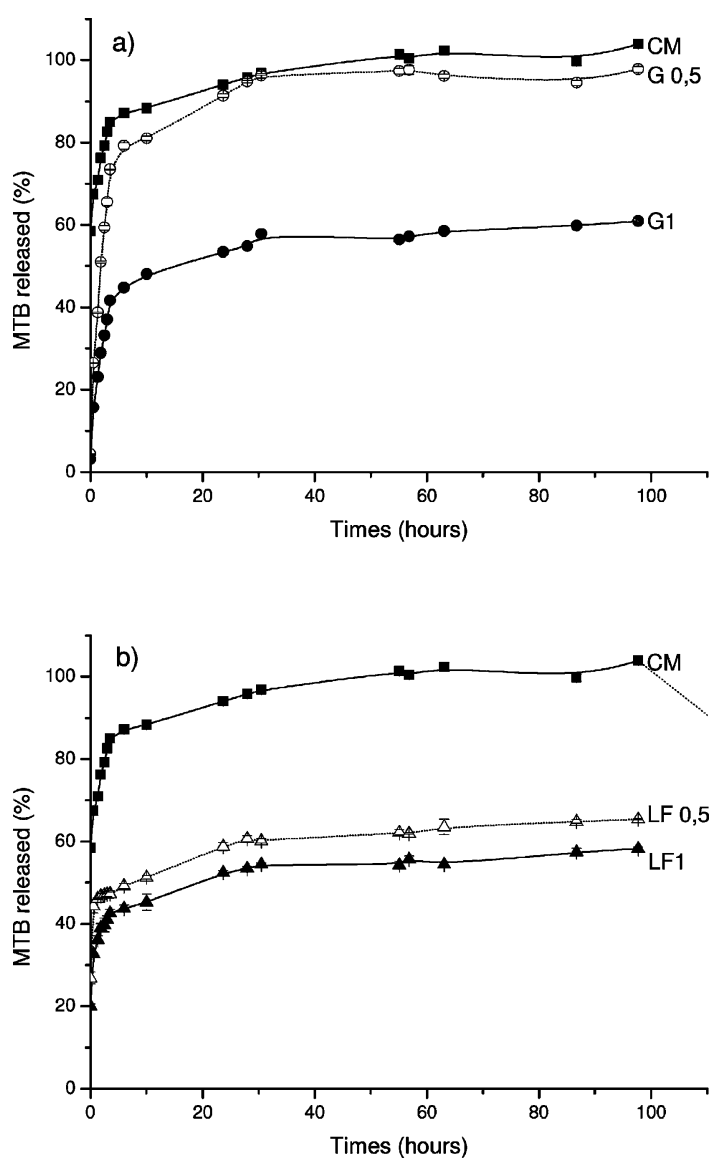

Figure 3. MTB released into water (\%) from the CRFs and CM.
The CRFs used in the dissipation experiments (G1, LF0.5, and LF1) were selected because of the slow- release experiments in comparison to the release from the $\mathrm{CM}$ formulation.

The experimental data on MTB degradation from all of the formulations studied (commercial and CRFs) on the three soils assayed showed an excellent fit to the single first-order (SFO) kinetic model. SFO degradation curves are shown in Figure 4. There was no initial lag phase, normally attributed to the adaptation of the microbial population, on any degradation curves. This behavior is often observed in the laboratory studies, where faster degradation is often followed by a slower decline in pesticide residues.

SFO degradation constants $(k)$ and half-lives $\left(\mathrm{DT}_{50}\right)$ deduced from the kinetic model are reported in Table 4. MTB degradation rates in all soils investigated were similar regardless when the herbicide was applied as gel-clay-based formulation or commercial formulation. This similarity was observed despite the fact that the water release of G1 was $60 \%$ compared to $100 \%$ for the CM and 65 and $58 \%$ for LF0.5 and LFl, respectively. The behavior of G1 could be due to the fact that the gel could increase the level of microbial activity in the formulation surroundings. The order of the MTB dissipation rate was $\mathrm{G} 1 \geq$ $\mathrm{CM}>\mathrm{LF} 0.5>\mathrm{LF} 1$. These results indicate the great influence of the formulation type on MTB dissipation in soil. The percentage of MTB degraded from the freeze-dried formulations LF 0.5 and LF1 was related to the rate of MTB release into water.

Influence of Soil Type on MTB Dissipation in Soils. Table 4 shows the degradation rate and $\mathrm{DT}_{50}$ for the soils studied. Overall, the MTB dissipation in all soils investigated was reduced when the herbicide was applied as lyophilized-gel-claybased formulation, especially in the case of LF1. When using CRFs, the soil where the decrease in degradation was most favorable was sandy soil with values of 104.1 and 57.5 days for LF1 and LF 0.5, respectively, versus 24.8 days for CM. These results are very important because sandy soils present more problems from an environmental point of view. Dowler et al. (33) and Sopeña et al. (34) observed a major persistence of alachlor and norflurazon in soils treated with CRFs. They attributed their persistence to the gradual release of the active ingredient from CRFs, because a part is kept confined in these formulations and thus protected from environmental losses. Regardless of the type of formulation, the order of the MTB dissipation rate in the soils studied was silt loam $<$ sandy $<$ clay (Table 4). This order reflects a direct relationship between the degradation rate and soil $\mathrm{pH}$, because herbicide degradation was decreased at low $\mathrm{pH}$ levels. The silt loam soil has the lowest $\mathrm{pH}$ of the studied soils (Table 1). These results are in agreement with previous studies $(18,6)$ that indicated that higher soil $\mathrm{pH}$ can be more favorable for microbial degradation of the herbicide.

Many studies have demonstrated a positive influence of $\mathrm{pH}$, microbial biomass, and microbial metabolic diversity on the degradation rate $(35,36)$. In our case, a direct relationship was observed between the bioactivity (DA) of the soils and the degradation rate (Table 1). The lowest rate of degradation was observed in the soil exhibiting the weakest bioactivity (silt loam soil), whereas clay soil showing the highest dehydrogenase activity was the soil with the highest MTB degradation and the lowest $\mathrm{DT}_{50}$ (Table 4).

A positive relationship was not found between the degradation rates and the $\mathrm{OM}$ content for all of the tested formulations, including the commercial MTB formulation as well. However, other authors (18) showed a positive relationship because of the enhanced bioactivity in soils having a larger OC content. 
CM

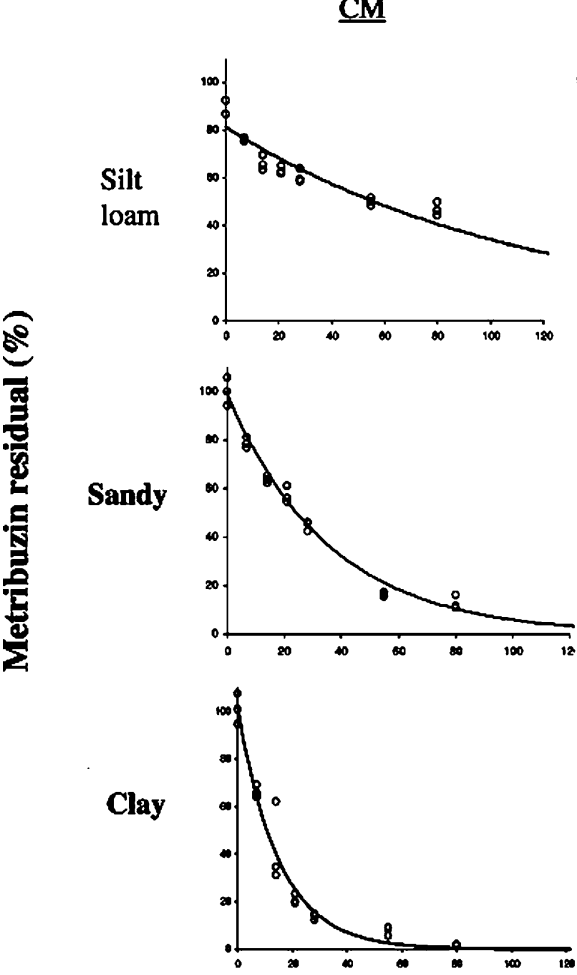

$\underline{\mathrm{LF} 0.5}$

$\underline{\text { LF1 }}$
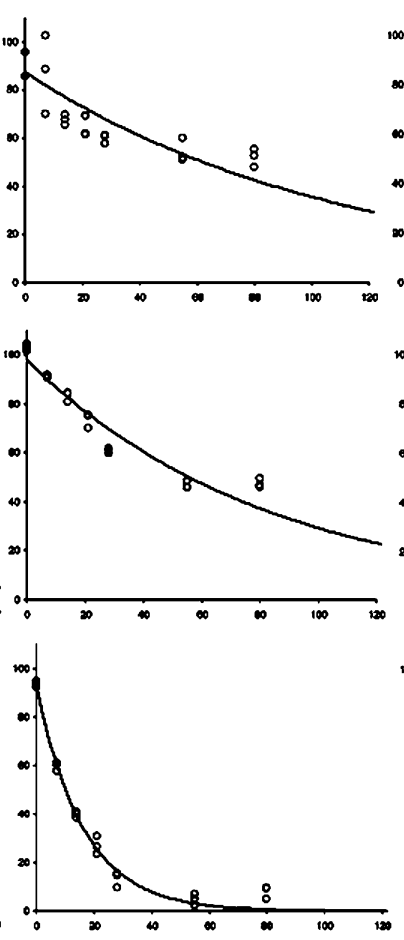

G1
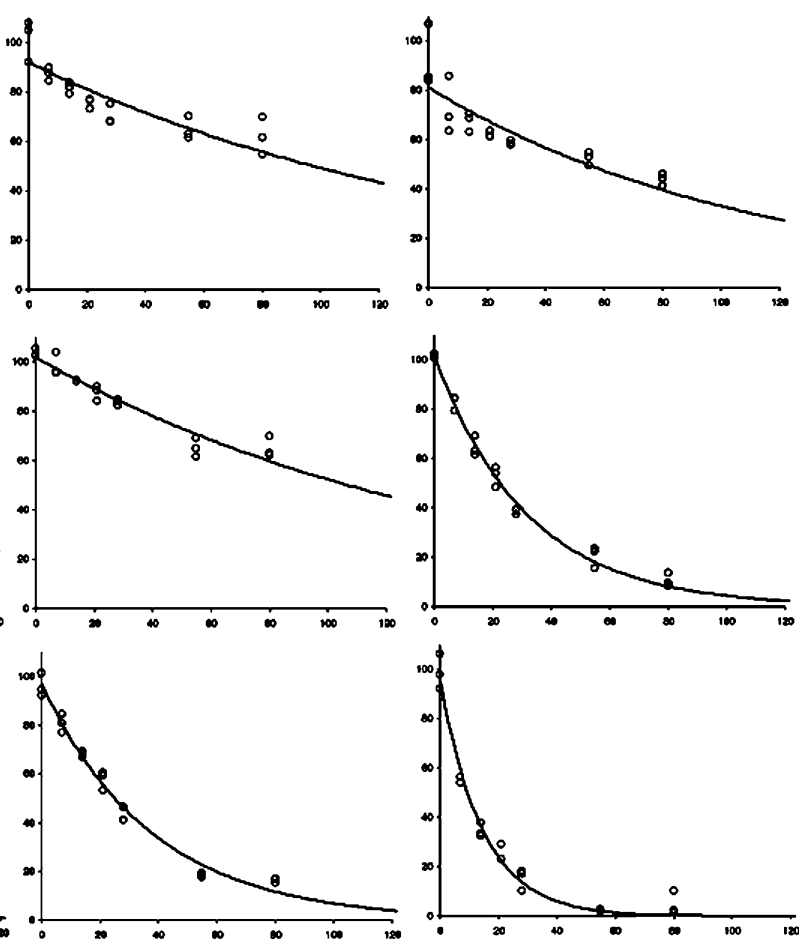

Time (days)

Figure 4. SFO kinetic MTB degradation curves in soils using the CM and three of the CRFs prepared.

Table 4. DT 50 (Days) and Degradation Rate Constants (Days ${ }^{-1}$ ) of MTB for the Three Soils

\begin{tabular}{|c|c|c|c|c|c|c|c|c|}
\hline \multirow[b]{2}{*}{ soils } & \multicolumn{2}{|c|}{$\mathrm{CM}$} & \multicolumn{2}{|c|}{ LF0.5 } & \multicolumn{2}{|c|}{ LF1 } & \multicolumn{2}{|c|}{ G1 } \\
\hline & $\overline{K\left(10^{-3}\right)}$ & $\mathrm{DT}_{50}$ & $\overline{K\left(10^{-3}\right)}$ & $\mathrm{DT}_{50}$ & $\overline{K\left(10^{-3}\right)}$ & $\mathrm{DT}_{50}$ & $\overline{K\left(10^{-3}\right)}$ & $\mathrm{DT}_{50}$ \\
\hline silt loam & 9 & $80.0_{( \pm 0.6)}$ & 9 & $77.4_{( \pm 0.2)}$ & 6 & $111.1_{( \pm 0.1)}$ & 9 & $77.3_{( \pm 0.8)}$ \\
\hline clay & 67 & $10.4_{( \pm 2.1)}$ & 62 & $11.2_{( \pm 1.1)}$ & 26 & $26.2_{( \pm 1.4)}$ & 70 & $10.0_{( \pm 2.3)}$ \\
\hline
\end{tabular}

The soils studied here show very low OM content and do not present a direct relationship between soil bioactivity (dehydrogenase activity) and OM content.

In conclusion, MTB degradation from all clay-gel-based formulations studied was influenced by $\mathrm{pH}$ and bioactivity of the investigated soils.

Link between Sorption-Desorption and Degradation Processes. The processes of adsorption and degradation have often been found to be correlated (37); however, there was no clear relationship between degradation $\left(K_{\mathrm{D}}\right)$ and sorption $\left(K_{\mathrm{f}}\right)$ for MTB in our selected soils. It is well-recognized that degradation processes can be rectricted to the soil solution, and those sorbed molecules may be protected from microbial attacks (38). However, the clay soil that presents the highest adsorption capacity of the studied soils showed the highest degradation rate, while the sandy soil and the silt loam soil showed opposite trends. The soils of the present study showed low adsorption capacity, and it is difficult to distinguish the influence of this process on degradation, because OM has a positive effect on sorption and degradation through the increase of bioactivity of soil. Therefore, it is difficult to distinguish the effect of the adsorption process on degradation. In addition, the percentage of MTB desorbed with respect to that which had been previously adsorbed during the adsorption process (\%D) is large, with values from 65 to $100 \%$ (Table 3).
MTB seems to be primarily degraded by microorganisms because of the relationship between the degradation rate and bioactivity.

Kah et al. (18) carried out sorption-degradation studies with six acidic pesticides and four basic pesticides, including MTB; they did not find a significant correlation between the sorption coefficient and degradation rates for MTB and for most of the other pesticides studied. On the contrary, Villaverde et al. (39) carried out adsorption and degradation experiments with four acidic pesticides and significant positive correlations were obtained between the adsorption coefficients and the degradation rate constant for three of the pesticides investigated, which was attributed to the higher number of microorganisms that could be formed near the adsorption point.

A relationship between degradation and adsorption is more likely for soils with similar properties (18); however, the soils of the current study present large differences in their physicochemical characteristics, and in consequence, these is a great influence of the different soil properties on the degradation processes. Therefore, a link between sorption and degradation processes is difficult to establish.

\section{ACKNOWLEDGMENT}

The authors thank Ms. Mirian Perez-Sayago for her assistance in carrying out the soil determinations. This work was supported 
by the Spanish Ministry of Education and Science (MEC) through Research Projects AGL 2005-00164, by Junta de Andalucía (project P06-FQM-01909), and by AECID (project A/016047/08). The authors are indebted to Presmar S.L. for providing MTB and Tolsa S.A. for the sepiolite used.

\section{LITERATURE CITED}

(1) Kjær, J.; Olsen, P.; Henriksen, J.; Ullum, M. Leaching of metribuzin metabolites and the associated contamination of a sandy Danish aquifer. Environ. Sci. Technol. 2005, 39, 83748381.

(2) Maloschik, E.; Ernst, A.; Hegeduss, G.; Darvas, B.; Szekacs, A. Monitoring water-polluting pesticides in Hungary. Microchem. J. 2007, 85, 88-97.

(3) The e-Pesticides Manual: A World Compendium; Tomlin, C. D. S., Eds.; The British Crop Production Council: Hamshire, U.K., 2006.

(4) Undabeytia, T.; Mishael, Y. G.; Nir, S.; Papahadjopoulos, D.; Rubin, B.; Morillo, E.; Maqueda, C. A novel system for reducing leaching from formulations of anionic herbicides: Clayliposomes. Environ. Sci. Technol. 2003, 3, 4475-4480.

(5) Sopeña, F.; Maqueda, C.; Villaverde, J.; Morillo, E. Reduction of pesticides pollution in agricultural soils by using controlled release formulations: Efficacy and persistencestudies. Fresenius Environ. Bull. 2008, 17, 10.

(6) Sopeña, F; Maqueda, C; Morillo, E. Influence of soil characteristics and formulation on alachlor dissipation in soil. Soil Sci. Soc. Am. J. 2008, 72, 767-774.

(7) Garrido-Herrera, F. J.; Gonzalez-Pradas, E.; Fernandez-Perez, M. Controlled release of isoproturon, imidacloprid, and cyromazine from alginate-bentonite-activated carbon formulations. J. Agric. Food Chem. 2006, 54, 10053-10060.

(8) Pepperman, A. B.; Kuan, J. W. Slow release formulations of metribuzin based on alginate-kaolin-linseed oil. J. Controlled Release 1993, 26, 21-30.

(9) Johnson, R. M.; Pepperman, A. B. Soil column mobility of metribuzin from alginate-encapsulated controlled-release formulations. J. Agric. Food Chem. 1995, 43, 241-246.

(10) Selim, H. M.; McGowen, S. L.; Johnson, R. M.; Pepperman, A. B. Fate of metribuzin from alginate controlled formulations in a sharkey soil: 2. Transport. Soil Sci. 1998, 16, 535-543.

(11) Flores-Cespedes, F.; Villafranca-Sanchez, M.; Perez-Garcia, S.; Fernandez-Perez, M. Modifying sorbents in controlled release formulations to prevent herbicides pollution. Chemosphere 2007, 6, 785-794.

(12) Rehab, A.; Akelah, A.; El-Gamal, M. M. Controlled-release systems based on the intercalation of polymeric metribuzin onto montmorillonite. J. Polymer Sci., Part A. Polym. Chem. 2002, 40, 2513-2525.

(13) Hermosin, M. C.; Celis, R.; Facenda, M. J.; Carrizosa, M. J.; Ortega-Calvo, J. J.; Cornejo, J. Bioavailability of the herbicide 2,4-D formulated with organoclays. Soil Biol. Biochem. 2006, 38 , 2117-2124.

(14) Singh, N. Reduced downward mobility of metolachlor and metribuzin from surfactant-modified clays. J. Environ. Sci. Health, Part B 2006, 41, 17-29.

(15) Kuang, W. X.; Facey, G. A.; Detellier, C.; Casal, B.; Serratosa, J. M.; Ruiz-Hitzky, E. Nanostructured hybrid materials formed by sequestration of pyridine molecules in the tunnels of sepiolite. Chem. Mater. 2003, 15, 4956-4967.

(16) Gonzalez-Pradas, E; Socias-Viciana, M; Urena-Amate, M. D.; Cantos-Molina, A.; Villafranca-Sanchez, M. Adsorption of chloridazon from aqueous solution on heat and acid treated sepiolites. Water Res. 2005, 39, 1849-1857.

(17) Khoury, R.; Coste, C. M.; Kawar, N. S. Degradation of metribuzin in two soil type of Lebanon. J. Environ. Sci. Health, Part B 2006, 41, 795-806.

(18) Kah, M.; Beulke, S.; Brown, C. D. Factors influencing degradation of pesticides in soil. J. Agric. Food Chem. 2007, 55, 4487-4492.

(19) Soil Survey Staff. Key to Soil Taxonomy, 10th ed.; Natural Resources Conservation Service (NRCS): Washinton, D.C., 2006.
(20) Gee, G. W.; Bauder, J. W. Particle-size analysis. In Methods of Soil Analysis: Part 1. Physical and Mineralogical Methods; Klute, A., Ed.; American Society of Agronomy: Madison, WI, 1986; Agronomy Series Number 9, pp 383-411.

(21) Demolon, A.; Leroux, D. Guide pour l'estude Experimental des Sols; Gautier Villars: Paris, France, 1952.

(22) Maqueda, C.; Villaverde, J.; Sopeña, F.; Undabeytia, T.; Morillo, E. A novel system for reducing leaching of the herbicide metribuzin using clay-gel-based formulations. J. Agric. Food Chem. 2008, 56, 11941-11946.

(23) Ma, L.; Southwick, L. M.; Willis, G. H.; Selim, M. Hysteristic characteristic of atrazine adsorption-desorption by a sharkey soil. Weed Sci. 1993, 41, 627-633.

(24) Morillo, E.; Maqueda, C.; Reinoso, R.; Undabeytia, T. Effect of two organic amendments on norflurazon retention and release by soils of different characteristics. Environ. Sci. Technol. 2002, 36, 4319-4325.

(25) Morillo, E.; Undabeytia, T.; Cabrera, A.; Villaverde, J.; Maqueda, C. Effect of soil type on adsorption-desorption, mobility, and activity of the herbicide norflurazon. J. Agric. Food Chem. 2004, $52,884-890$.

(26) Undabeytia, T.; Sanchez-Verdejo, T.; Morillo, E.; Maqueda, C. Effect of organic amendments on the retention and mobility of imazaquin in soils. J. Agric. Food Chem. 2004, 52, 4493-4500.

(27) FOCUS. Guidance document on estimating persistence and degradation kinetics from environmental fate studies on pesticides in EU registration. Report of the FOCUS Work Group on Degradation Kinetics, EC Document Reference Sanco/10058/ 2005, version 2.0, 2006.

(28) Giles, C. H.; MacEwan, T. H.; Nekhwa, S. N.; Smith, D. Studies in adsorption. Part 11. A system of classification of solution adsorption isotherms, and its use in diagnosis of adsorption mechanisms and measurement of specific surface area of solids. J. Chem. Soc. 1960, 3973-3993.

(29) Majumdar, K.; Singh, N. Effect of soil amendments on sorption and mobility of metribuzin in soils. Chemosphere 2007, 66, 630637.

(30) Harper, S. S. Sorption of metribuzin in surface and subsurface soils of the Mississippi Delta region. Weed Sci. 1988, 36, 84-90.

(31) Barriuso, E.; Calvet, R.; Cure, B. Impact of reduced-tillage systems on the behavior of pesticides-Significance for the risk of pollution. Reduced Tillage Syst. 1994, 65, 105-124.

(32) Selim, H. M. Retention and runoff losses of atrazine and metribuzin in soil. J. Environ. Qual. 2003, 32, 1058-1071.

(33) Dowler, C.; Dailey, O.; Mullinick, B. Polymeric microcapsules of alachlor: Preparation and evaluation of controlled release properties. J. Agric. Food Chem. 1999, 47, 2908-2913.

(34) Sopeña, F.; Maqueda, C.; Morillo, E. Norflurazon mobility, dissipation, activity, and persistence in a sandy soil as influenced by formulation. J. Agric. Food Chem. 2007, 55, 3561-3567.

(35) Walker, A.; Jurado-Exposito, M.; Bending, G. D.; Smith, V. J. R. Spatial variability in the degradation rate of isoproturon in soil. Environ. Pollut. 2001, 111, 407-415.

(36) Price, O. R.; Walker, A.; Wood, M.; Oliver, M. A. Using geostatistics to evaluate spatial variation in pesticide/soil interactions. Symposium on Pesticide Behaviour in Soils and Water, Brighton, U.K., 2001; Vol. 78, pp 233-238.

(37) Dyson, J. S.; Beulke, S.; Brown, C. D.; Lane, M. C. G. Adsorption and degradation of the weak acid mesotrion in soil and environmental fate implications. J. Environ. Qual. 2002, 31, 613-618.

(38) Radosevich, M.; Traina, S. J.; Tuovinen, O. H. Biodegradation of atrazine in surface soil sand subsurface sediments collected from agricultural research farm. Biodegradation 1996, 7, 137-140.

(39) Villaverde, J.; Kah, M.; Brown, C. D. Adsorption and degradation of four acidic pesticides in soils from southern Spain. Pest. Manage. Sci. 2008, 64, 703-710.

Received for review December 10, 2008. Revised manuscript received February 17, 2009. Accepted February 19, 2009.

JF803819Q 